\title{
KARATERSTIK PRESSURE COEFFICENT (CP) PADA ALIRAN SETELAH MELEWATI CYCLONE DENGAN DUA DINDING EFEKTIF
}

\author{
Oleh \\ Gede Widayana \\ Jurusan Pendidikan Teknik Mesin, FTK, UNDIKSHA
}

\begin{abstract}
ABSTRAK
Perkembangan di bidang otomotif belakangan ini sangat pesat, perbaikan demi perbaikan terus dilakukan dalam upaya untuk meningkatkan unjuk kerja mesin. Upaya tersebut dapat dilakukan dengan pembuatan desain baru secara keseluruhan yang lebih baik atau dengan memberikan peralatan tambahan pada mesin yang sudah ada. Generasi terbaru dari cyclone adalah jenis Internal Flow Cyclone, sedikit berbeda dari dari tipe sebelumnya, cyclone jenis ini ditempatkan setelah karburator sebelum masuk ruang bakar. Penambahan ini berguna untuk meningkatkan homogenitas campuran udara dan bahan bakar.

Tujuan dari penelitian ini adalah untuk menghilangkan daerah separasi inlet cyclone sehingga menghasilkan generasi kedua dari cyclone yaitu Cyclone dengan Dua Dinding Efektif kemudian dicari seberapa besar karateristik Pressure Coefficent (Cp) Pada Aliran Setelah Melewati Cyclone dengan Dua Dinding Efektif ini.

Cyclone dengan dua dinding efektif mampu menguragi effect blockage pada daerah central area of inner passage dan pada outer passage, terlihat dari semakin mengecilnya harga Pressure Coefficent (Cp) pada kedua area tersebut.
\end{abstract}

Kata-kata kunci : Pressure Coefficent (Cp), Cyclone, Internal Flow Cyclone.

\begin{abstract}
The expands is in the otomotif lately very fast, repair non-stoped to done in the effort to increase work the machine. The effort can done with the better new making desain as a whole or by giving additional equipments at machine. Newest generation from cyclone is Internal Flow Cyclone, a few/little differing from from previous type, cyclone of this type of placed by after carburettor before entering space burn. This addition good for improving homogeneity of mixture of air and fuel. Intention of this research is to eliminate the area of separation of inlet cyclone so that yield the second generation from cyclone that is Cyclone with Two Effective Wall , later;then searched how big karateristik Pressure Coefficent ( $\mathrm{Cp}$ ) of Stream After pass Cyclone with Two Effective Wall.

Cyclone with two effective wall able to decrease effect blockage at area of central of inner passage and outer passage, seen from progressively minimize price of Pressure Coefficent ( $\mathrm{Cp}$ ) at second of the area.
\end{abstract}

Keywords : Pressure Coefficent ( Cp), Cyclone, Internal Flow Cyclone. 


\section{PENDAHULUAN}

Perkembangan di bidang otomotif belakangan ini sangat pesat, perbaikan demi perbaikan terus dilakukan dalam upaya untuk meningkatkan unjuk kerja mesin. Upaya tersebut dapat dilakukan dengan pembuatan desain baru secara keseluruhan yang lebih baik atau dengan memberikan peralatan tambahan pada mesin yang sudah ada. Salah satu cara untuk meningkatkan performa mesin yang sudah diperkenalkan pada masyarakat luas adalah dengan penambahan alat yang disebut Turbo Cyclone.

Penambahan Turbo Cyclone yang ditempatkan pada filter udara masuk sebelum masuk karburator mampu memberikan aliran swirl yang lebih baik sehingga pada akhirnya dapat meningkatkan homogenitas campuran antara udara dengan bahan bakar. Alat ini terbuat dari logam stainless steel yang mempunyai beberapa sirip/sudu datar tipis dengan kemiringan tertentu terhadap sumbu tegaknya yang berfungsi mengarahkan udara sebelum masuk ke karburator agar bergerak membentuk aliran swirl saat piston melakukan langkah hisap.

Generasi terbaru dari cyclone adalah jenis Internal Flow Cyclone, sedikit berbeda dari dari tipe sebelumnya, cyclone jenis ini ditempatkan setelah karburator sebelum masuk ruang bakar. Penambahan ini berguna untuk meningkatkan homogenitas campuran udara dan bahan bakar.

Timbulnya aliran swirl karena penambahan turbo cyclone ini sebenarnya disebabkan karena adanya sudu/sirip tipis pada konstruksi turbo cyclone, yang dibentuk dan ditempatkan sedemikian rupa sehingga aliran udara yang masuk melewatinya membentuk suatu olakan ( swirl). Secara simultan olakan tersebut akan bercampur membentuk aliran 3 dimensi ( $3 \mathrm{D}$ flow ) pada daerah percampuran . 3 D flow sendiri pada hakekatnya merupakan aliran sekunder sebagai hasil separasi aliran dalam bentuk tiga dimensi.

Dengan mengacu pada hal-hal yang dikemukakan diatas maka dilakukan serangkaian pengujian terhadap peralatan cyclone yang merupakan modifikasi dari turbo cyclone sedemikian sehingga penempatan sudu-sudunya digantikan dengan sebuah saluran yang terpilin untuk meneliti karateristik Pressure Coefficent (Cp) 
Pada Aliran Setelah Melewati Cyclone dengan Dua Dinding Efektif yang terjadi pada outletnya.

Pada Internal Flow Cyclone terjadi efek yang sama seperti pada penggunaan sudu lengkung pada turbo cyclone, yaitu membuat aliran fluida yang masuk melewatinya dituntun dan diarahkan dengan lebih baik untuk lebih membentuk olakan dan begitu juga separasi yang terjadi sehingga pencampuran aliran fluida semakin simultan yang pada akhirnya menyebabkan karateristik aliran 3 dimensi yang terbentuk lebih besar.

Dengan menambahkan dua dinding efektif akan menghilangkan ketidakstabilan aliran pada dinding saluran dan diharapkan akan memperbesar rambatan karateristik aliran 3 dimensi dari dinding menuju tengah saluran dengan sebaran yang merata, yang mana nantinya campuran fluida setelah melewati Cyclone dengan Dua Dinding Efektif akan semakin simultan.

Ketika melewati saluran setelah outlet cyclone, aliran swirl mempunyai karateristik 3 dimensi yang berbeda-beda di sepanjang saluran, dimana pada awalnya relatif besar dan kemudian mengecil hingga akhirnya mengalami relaksasi yang diindikasikan dengan perbedaan tekanan rata-rata dinding antara sesaat setelah memasuki saluran dengan titik ukur sepanjang arah aksial.

Untuk mengetahui seberapa besar karateristik Pressure Coefficent (Cp) Pada Aliran Setelah Melewati Cyclone dengan Dua Dinding Efektif yang terbentuk sepanjang saluran dilakukan pengujian aerodinamis terhadap Cyclone dengan Dua Dinding Efektif untuk mendapatkan profil karateristik Pressure Coefficent $(\mathrm{Cp})$ yang ditampilkan dalam bentuk 3 dimensi.

Tujuan dari penelitian ini adalah untuk menghilangkan daerah separasi inlet cyclone sehingga menghasilkan generasi kedua dari cyclone yaitu Cyclone dengan Dua Dinding Efektif kemudian dicari seberapa besar karateristik Pressure Coefficent (Cp) Pada Aliran Setelah Melewati Cyclone dengan Dua Dinding Efektif ini. 


\section{METODE PENELITIAN}

Eksperimen yang dilakukan menggunakan saluran uji $\mathrm{d}=0,35 \mathrm{~m}$, panjang 1,20 m, model cyclone saluran terpilin IFC2SW, Blower dengan daya $2 \mathrm{~kW}$ putaran $2850 \mathrm{rpm}$ dan blade $\mathrm{d}=0,33 \mathrm{~m}$, pitot static tube, five-holes probe, hoelder dan traveler mechanism, inclined manometer dengan fluida kerosene $(\mathrm{SG}=0,815)$ sudut kemiringan $15^{\circ}$ dan diameter lubang $1 \mathrm{~mm}$.

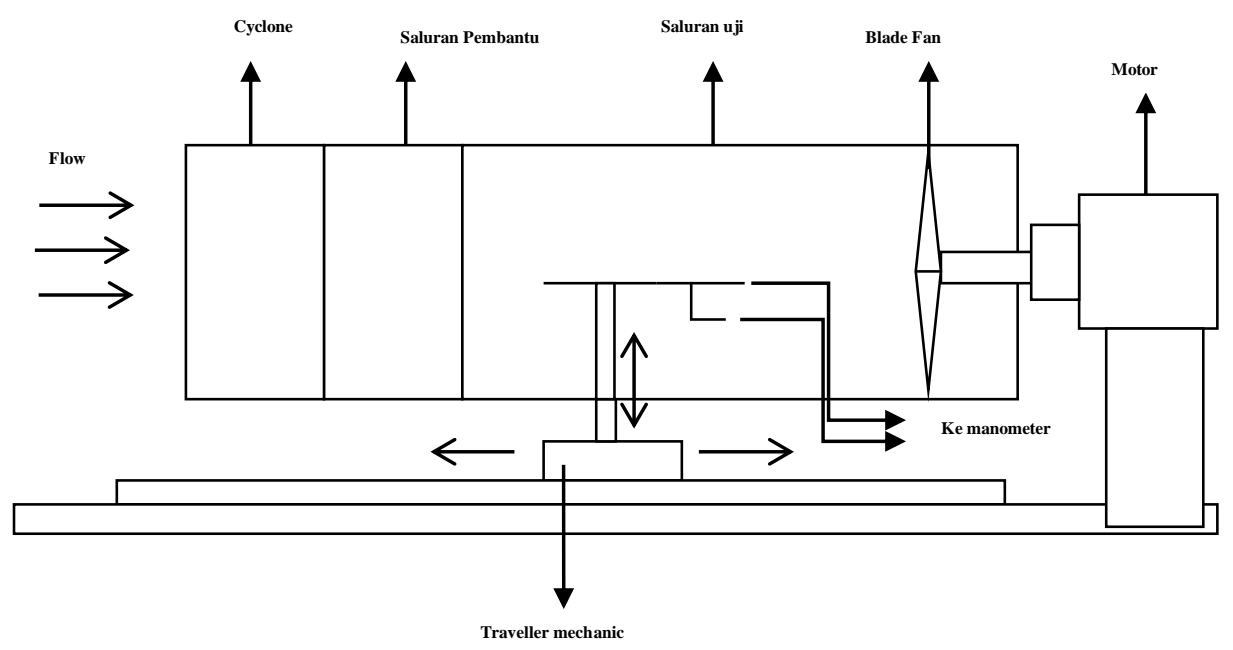

Gambar 1. Skema Peralatan Untuk Mengukur Medan Aliran.
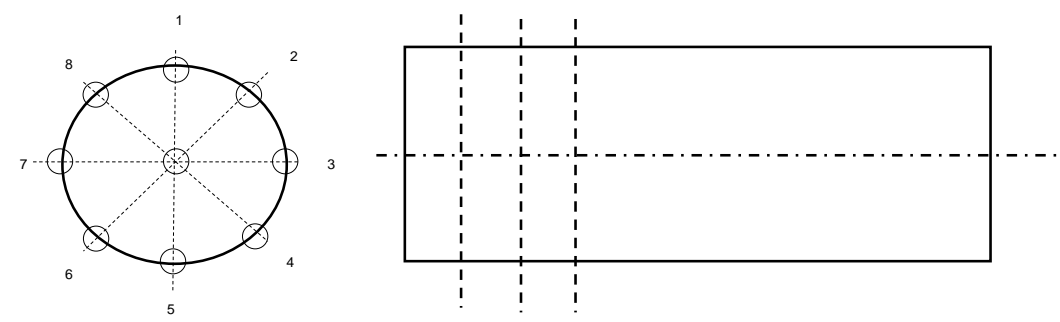

Gambar 2. Skema Pengukuran Tekanan Statis pada dinding dan pusat saluran uji. 


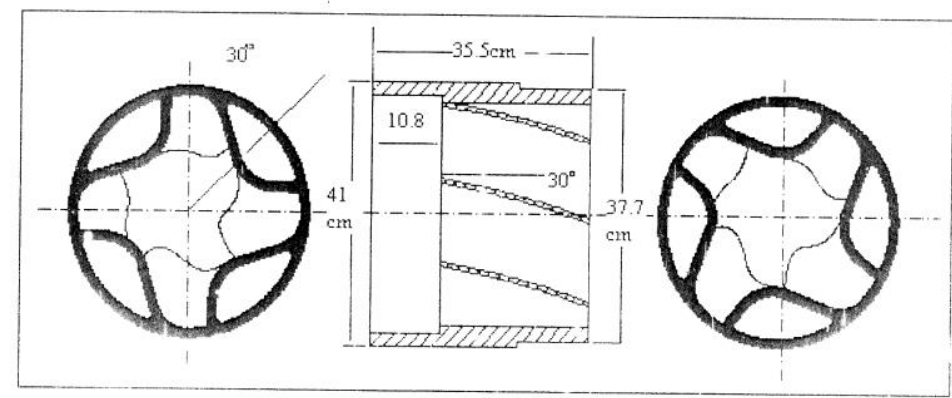

(a)

(b)

(c)

Gambar 3. Model Cyclone dengan 2 dinding Efektif a).Inlet Cyclone b). Penampang Cyclone c). Outlet Cyclone

\section{HASIL DAN PEMBAHASAN}

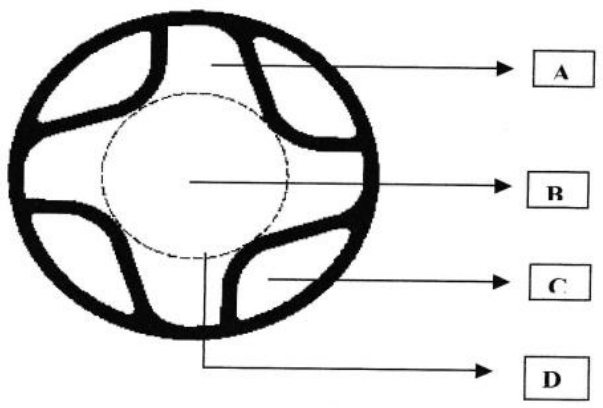

Gambar 4. Skema pembagian area aliran pada outlet Cyclone Keterangan :
A. Corner Area of Inner Passage
B. Centrak Area of Inner Passage
C. Outer Passage
D. Ring Area of Inner Passage

Hasil penelitian performa dari Cyclone dengan dua dinding efektif dapat dijelaskan dengan bantuan Gambar 4 . Pada Gambar 4 tersebut area keluaran outlet Cyclone dengan dua dinding efektif terbagi atas saluran utama yang dinamakan dengan inner passage serta empat buah saluran pembantu yang dinamakan dengan 
outer passage. Daerah inner passage yang berpenampang mirip bintang terbagi lagi atas dua sektor,yaitu central area of inner passage dan corner area of inner passage. Antara central area dan corner area dibatasi oleh lingkaran imaginer yang dinamakan ring area of inner passage. Pembagian ini semata-mata hanya bertujuan untuk mempermudah penjelasan selanjutnya.

Untuk mengetahui karateristik medan Presure Coefficent (Cp) setelah melewati Cyclone dengan dua dinding efektif maka dilakukan pengukuran yaitu tekanan statis di penampang yang berjarak $\mathrm{x} / \mathrm{D}=0, \mathrm{x} / \mathrm{D}=1, \mathrm{x} / \mathrm{D}=2$. Dari pengukuran tekanan statis akan didapat Presure Coefficent (Cp) aliran.

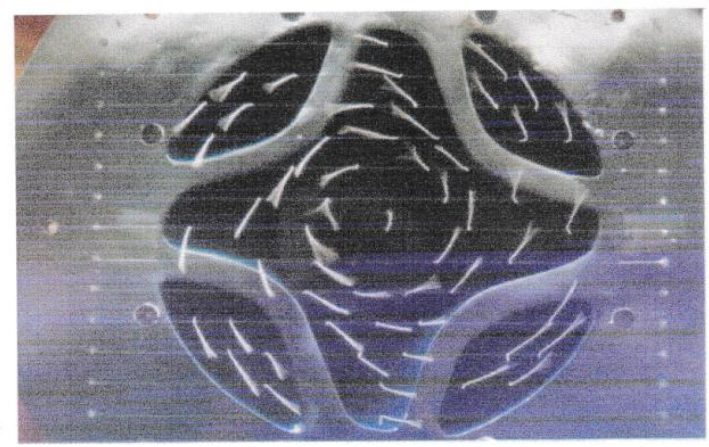

Gambar 5. Profil aliran pada outlet Cyclone

\subsection{Presure Coefficent (Cp)}

Pressure coefficient dapat didefinisikan sebagai angka yang menunjukkan perbandingan antara selisih tekanan statis lokal di suatu titik keluaran cyclone terhadap tekanan dinamis rata-rata aliran sebelum masuk cyclone. Dari sini dapat dipahami bahwa besarnya harga pressure coefficient di suatu titik pada aliran menunjukkan bahwa tekanan statis di titik tersebut juga besar.

\subsection{Distribusi Pressure Coefficent (Cp) Pada suatu Penampang.}

Dari hasil eksperimen yang ditampilkan pada gambar terlihat pola dimana harga $\mathrm{Cp}$ cenderung mengecil baik di central area of inner passage dan pada outer passage. Hal ini terjadi karena tekanan statis lokal semakin mengecil di kedua sektor tersebut . Ini akibat dari dampak yang mengiringi naiknya kecepatan aksial serta 
akibat dari berkurangnya blockage effect yang ditimbulkan oleh dominasi kecepatan sekunder.

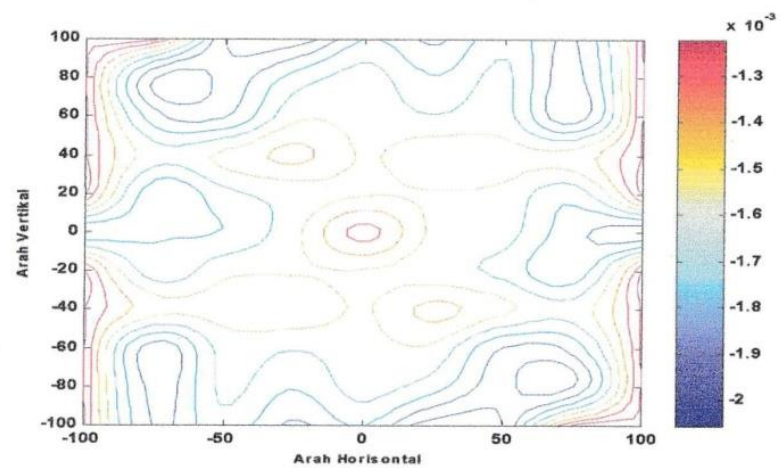

Gambar 6.Kontur Pressure Coefficent $(\mathrm{Cp})$ pd Penampang saluran berjarak $\mathrm{x} / \mathrm{D}=0$ dari outlet Cyclone.

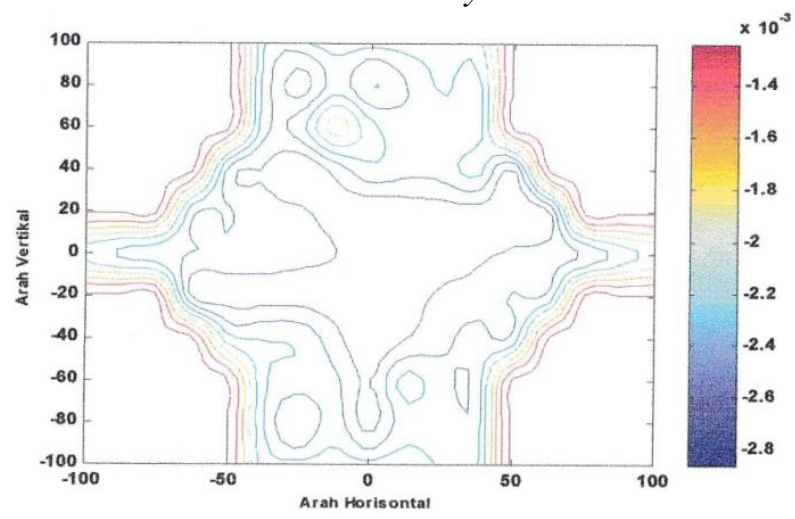

Gambar 7.Kontur Pressure Coefficent $(\mathrm{Cp})$ pd Penampang saluran berjarak $\mathrm{x} / \mathrm{D}=1$ dari outlet Cyclone.

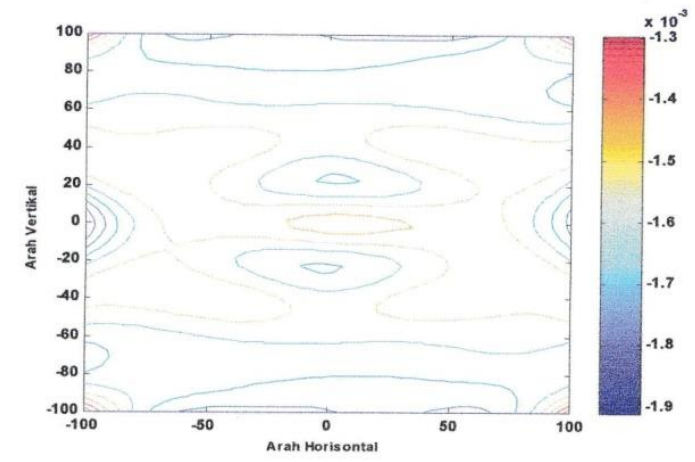

Gambar 8.Kontur Pressure Coefficent (Cp) pd Penampang saluran berjarak x/D=2 dari outlet Cyclone. 
Hal yang sedikit berbeda dijumpai pada daerah sekitar pusat saluran. Hasil penelitian menampakkan bahwa pada daerah ini blockage effect bersifat tidak kontinu, dimana pada saat fenomena tersebut muncul akan ditandai dengan meningkatnya harga pressure coefficient di daerah tersebut. Hal ini menunjukkan bahwa pada $\mathrm{x} / \mathrm{D}=1$ pengaruh blockage effect yang ditimbulkan oleh kecepatan sekunder sangat kuat pada ring area of inner passage, sedemikian sehingga berdampak pada bergesernya kecepatan aksial ke arah central area of inner passage dalam jumlah yang relative lebih besar dari x/D sebelumnya. Secara jelas hal ini diperlihatkan pada Gambar 8 yang memperlihatkan puncak berwarna merah pada area yang kecil dipusat aliran.

\subsection{Distribusi Pressure Coefficent (Cp) Dalam Arah Aksial}

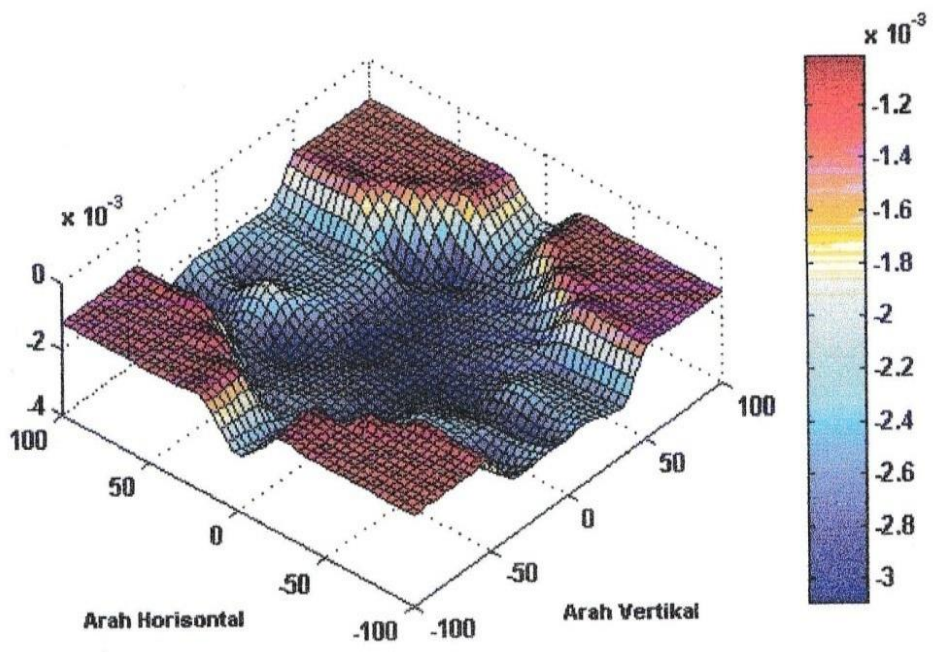

Gambar 9.Kontur Pressure Coefficent (Cp) 3 dimensi pd Penampang saluran berjarak $\mathrm{x} / \mathrm{D}=0$ dari outlet Cyclone. 


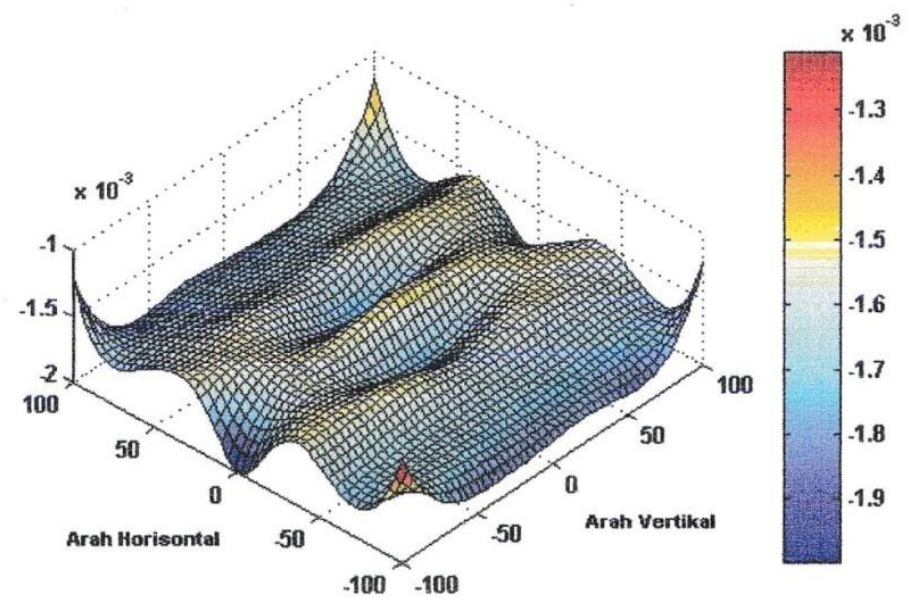

Gambar 10.Kontur Pressure Coefficent (Cp) 3 dimensi pd Penampang saluran berjarak $\mathrm{x} / \mathrm{D}=1$ dari outlet Cyclone.

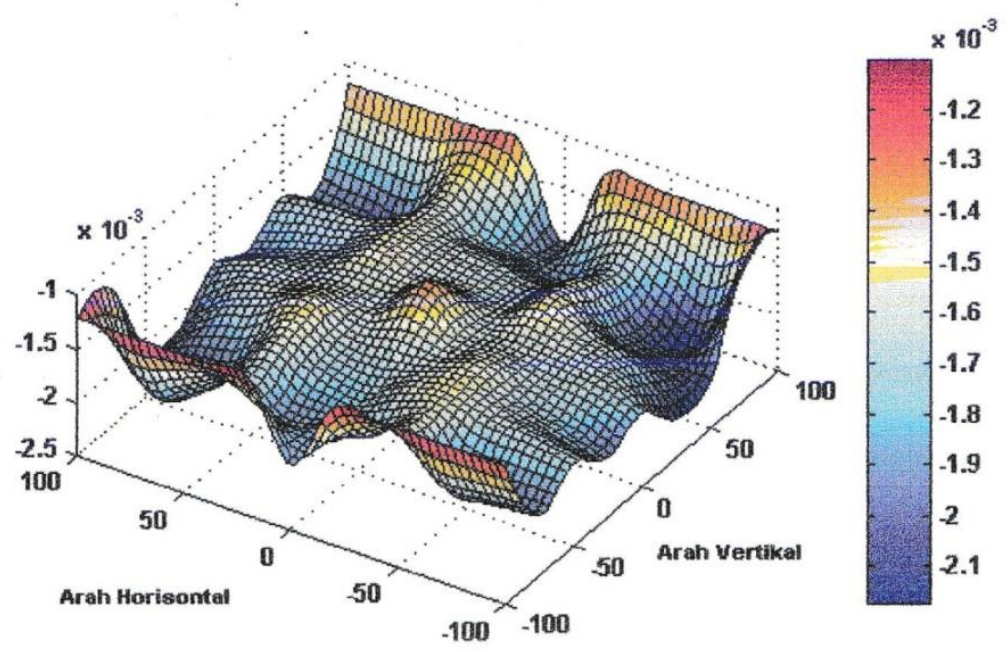

Gambar 11.Kontur Pressure Coefficent (Cp) 3 dimensi pd Penampang saluran berjarak $\mathrm{x} / \mathrm{D}=2$ dari outlet Cyclone.

Bentuk kontur 3 dimensi dari pressure coefficient $(\mathrm{Cp})$ mempunyai tren dalam arah aksial cenderung menyebar ke seluruh sektor aliran. Dari Gambar 11 terlihat bahwa harga pressure coefficient $(\mathrm{Cp})$ minimum yang berada disekitar central area of inner passage dan outer passage cenderung menyebar merata seiring dengan bertambah jauhnya jarak dari outlet cyclone. Hal ini jelas berkaitan erat dengan 
berkurangnya efek blockage yang berakibat pada terdistribusiya kecepatan aksal secara lebih merata.

\section{PENUTUP}

Cyclone dengan dua dinding efektif mampu menguragi effect blockage pada daerah central area of inner passage dan pada outer passage, terlihat dari semakin mengecilnya harga Pressure Coefficent $(\mathrm{Cp})$ pada kedua area tersebut.

\section{DAFTAR PUSTAKA}

Mathur , M.L,R.P, 1980, A Couse in Internal Cobustion Engine, New Delhi, Dhanpat Rai \& Sons .

Fox,R.W and Mc Donald,A.T ,1985, Introduction to Fluid Mechanics, New York, John Willey and Sons,.

Anderson,John D, 1985,Fundamentals of Aerodynamics, New York, McGraw-Hill Book Company.

Sasongko,H.,1994,'Eichung du Beiden Modifizierten Conrad-Soden fur den Gitterwindkanal des Instituts fur Sromungmechanik", Braunschweigh , Instituts fur Sromungmechanik Technische Universitat Braunsweigh.

Indriano, W.,2001,'Studi Eksperimental tentang Karateristik Medan Aliran Tiga Dimensi pada Saluran Outlet dari Model Internal Flow Cyclone (IFC)",Surabaya, Teknik Mesin FTI-ITS.

Dwijendra,K.,2001,"Studi Eksperimental Medan Aliran Hilir di Belakang Internal Flow Cyclone (IFC) dengan Penuntun Aliran Masuk", Surabaya, Teknik Mesin FTI-ITS. 